\title{
Evolução e diferenciação dos sistemas agrários de Rolador-RS: trajetórias de um desenvolvimento desigual
}

\author{
Jeferson Tonin ${ }^{1}$ \\ José Tobias Marks Machado ${ }^{2}$ \\ Daniela Garcez Wives ${ }^{3}$
}

\begin{abstract}
Resumo
Objetivou-se com este trabalho reconstruir a evolução e a diferenciação dos sistemas agrários do município de Rolador-RS, bem como levantar algumas reflexões sobre o seu processo de desenvolvimento rural. Para isso, utilizou-se da Teoria dos Sistemas Agrários, a partir da qual se realizou um zoneamento e uma reconstrução no tempo dos sistemas agrários. Há, na região, uma tendência à utilização de sistemas de produção extensivos e baseados no ganho de escala. Estes sistemas de produção em pouco contribuem para um desenvolvimento equitativo e inclusivo, uma vez que são caracterizados pela concentração da renda e pela liberação de grandes contingentes populacionais.
\end{abstract}

Palavras-chaves: Desenvolvimento e crise. Modernização da agricultura. Desigualdade social.

\begin{abstract}
The aim of this work was to reconstruct the evolution and differentiation of the agrarian systems of the municipality of Rolador-RS, as well as to reflect on the process of rural development. For this, it was used of the theory of the Agrarian Systems, from which a zoning and a reconstruction of the agrarian systems in time was realized. There is a tendency in the region to use extensive production systems based on gain in scale. These production systems do little to contribute to equitable and inclusive development, since they are characterized by the concentration of income and the release of large numbers of people.
\end{abstract}

Keywords: Development and crisis. Modernization of agriculture. Social inequality.

\section{Introdução}

O município de Rolador está situado na área de abrangência do COREDE - Missões (Conselho Regional de Desenvolvimento - Missões) e, portanto, localiza-se à noroeste no estado do Rio Grande do Sul. Trata-se de um município com emancipação política bastante recente (1996), uma vez que pertencia até então ao município vizinho de São Luiz Gonzaga na condição de distrito.

\footnotetext{
${ }^{1}$ Doutorando em Desenvolvimento Rural pelo Programa de Pós-Graduação em Desenvolvimento Rural (PGDR-UFRGS). Técnico em Agropecuária do Instituto Federal Farroupilha, Campus Frederico Westphalen. jeferson.tonin@hotmail.com

2 Doutorando no Programa de Pós-Graduação em Desenvolvimento Rural da Universidade Federal do Rio Grande do Sul (PGDR/UFRGS). tobias.machado@hotmail.com

${ }^{3}$ Doutora em Desenvolvimento Rural. Professora no Programa de Pós-Graduação em Desenvolvimento Rural da Universidade Federal do Rio Grande do Sul (PGDR/UFRGS). garcezd@gmail.com
} 
Rolador dispõe de uma área de $295 \mathrm{Km}^{2}$ e possui uma população de aproximadamente 2.546 habitantes, sendo majoritariamente rural (77\%). É importante destacar que, por se tratar de uma área razoavelmente pequena, a proximidade com as sedes urbanas dos municípios vizinhos é grande e, em função disso, há um trânsito muito intenso entre estes, principalmente para fins comerciais.

O município encontra-se em uma posição geográfica singular, uma vez que, em seus limites, observam-se dois diferentes compartimentos de vegetação: região de floresta e região de campo. Esta divisão se traduz em linhas de evolução do espaço agrário bastante distintas, o que influenciou profundamente a ocupação das terras do Rio Grande do Sul (ZARTH, 1997; MIGUEL, 2013). No estado, extensas áreas de criação de gado geralmente caracterizavam as regiões ocupadas por campo. Assim, historicamente, essas regiões mantiveram sua estrutura fundiária consideravelmente concentrada, de forma que o índice de Gini da estrutura fundiária do município é maior que o índice de Gini da renda - 0,52 e 0,42, respectivamente. Nas áreas de floresta, por outro lado, o índice da estrutura fundiária tende a indicar menor concentração, uma vez que grande parte das terras foi dividida em lotes e, posteriormente, utilizada para colonização.

Esta dualidade que se apresenta no contexto agrário do município de Rolador desencadeia uma série de processos históricos específicos e, provavelmente, possui profundas implicações com a grande desigualdade social que hoje se observa, visto que é possível constatar sistemas de produção altamente capitalizados e operados em grande escala, mas também há aqueles que ocupam uma posição pouco privilegiada do ponto de vista de sua reprodução social e do desenvolvimento rural.

Dessa forma, o objetivo principal deste trabalho é reconstruir a evolução e a diferenciação dos sistemas agrários do município de Rolador-RS, bem como levantar algumas reflexões sobre o seu processo de desenvolvimento rural. Para isso, a estrutura deste trabalho foi dividida em quatro partes além desta introdução e da conclusão. Primeiramente, far-se-á uma breve descrição dos procedimentos metodológicos, bem como dos principais conceitos e sua operacionalização. A seguir, será realizada a descrição do zoneamento regional e suas implicações. Na terceira parte, serão reconstituídas a evolução e diferenciação dos sistemas agrários do presente município, e, por fim, será realizada uma discussão a respeito dos condicionantes de um desenvolvimento desigual. 


\section{Teoria dos sistemas agrários}

A elaboração deste trabalho teve como orientação teórica a abordagem sistêmica, que surge ao longo do século XX, em diferentes áreas do conhecimento. O avanço da ciência nesta época apontou os limites e limitações da abordagem cartesiana (amplamente utilizada desde o século XVII), de forma que a impossibilidade de explicar e compreender comportamentos e fenômenos naturais ditos complexos tornava-se cada vez mais evidente (MIGUEL, MAZOYER; ROUDART, 2009; SCHMITZ, 2005). Assim, para os autores, a abordagem sistêmica pode proporcionar uma visão de conjunto, fortemente estruturada e articulada, do fenômeno em estudo e deste com seu entorno. O conceito sistêmico exprime, simultaneamente, as noções de unidade, multiplicidade, totalidade, diversidade, organização e complexidade (MORIN, 1977).

A abordagem sistêmica, no âmbito das ciências agrárias, surge inicialmente como reação a visões puramente disciplinares dos problemas agrícolas, de forma que atualmente, embora heterogêneo, constitui um campo de estudo já consolidado (SILVA NETO; BASSO, 2015). Para este trabalho, utilizou-se a Teoria dos Sistemas Agrários tal qual descrita por Mazoyer e Roudart (2010), na medida em que se caracteriza como um instrumento intelectual que permite apreender a complexidade de cada forma de agricultura e de perceber, em grandes linhas, as transformações históricas e a diferenciação das agriculturas do mundo (MAZOYER; ROUDART, 2010).

Para Silva Neto e Basso (2015), sistema agrário corresponde a um conjunto de conhecimentos metodicamente elaborados como resultado da observação, da delimitação e da análise de uma agricultura particular, ou seja, não se trata de um objeto real, diretamente observável, mas de um objeto cientificamente elaborado, cuja finalidade não é retratar a agricultura em toda a sua complexidade, tarefa praticamente impossível, mas tornar essa complexidade inteligível segundo os objetivos específicos definidos.

Analisar e conceber um objeto complexo e animado em termos de sistema é também considerar seu funcionamento como uma combinação de funções interdependentes e complementares, que asseguram a circulação interna e as mudanças com o exterior de matéria, de energia (MAZOYER; ROUDART, 2010). Desse modo, a agricultura praticada em dado momento e lugar consiste em decompor essa mesma agricultura em dois subsistemas 
principais - o ecossistema cultivado e o sistema social produtivo -, estudando tanto a organização e o funcionamento de cada um desses subsistemas como suas inter-relações (MIGUEL; MAZOYER; ROUDART, 2009).

O ecossistema cultivado é decomposto em subsistemas complementares e proporcionados, de forma que para cada um destes há uma organização e uma exploração específicas, como hortas, terras cultiváveis e pastagem (MAZOYER; ROUDART, 2010). O sistema social, conforme Wives (2013), por sua vez, configura-se por ser o espaço do núcleo familiar de formulação e implantação de ações, com vistas a atingir seu(s) objetivo(s). Em outras palavras, no interior do sistema social, ocorre o processo de tomada de decisão, implicando as formas de organização dos ativos terra, trabalho e capital, combinando ações de curto (sistema controle) e de longo (sistema fins) prazo, recombinando-as no decorrer do tempo. O tempo implica, nessa perspectiva, considerar as interdependências e as emergências no sistema.

De posse desse ferramental metodológico, delimitou-se um espaço geográfico e fezse uma análise de paisagem, atentando-se para características como formação geofísica, vegetação e relevo, e, com o objetivo de descrever as diferentes paisagens agrárias da localidade, estabeleceu-se um zoneamento regional. Após isso, construiu-se a evolução e a diferenciação dos sistemas agrários do município de Rolador ao longo do tempo. Para realizar as delimitações de cada sistema agrário, utilizaram-se alguns critérios norteadores: i) paisagem; ii) exploração predominante; iii) meios de produção; iv) mão de obra; v) excedente agrícola; vi) índice de capitalização; vii) condições de transição.

Os dados descritos neste trabalho são oriundos de visitas a campo, entrevistas realizadas com agricultores e agricultoras do município, análise de mapas já disponíveis e bibliografia local. O período de coleta desses dados ocorreu durante o segundo semestre de 2016.

\section{Zoneamento regional}

Como já mencionado, as duas grandes formações vegetais - campo e floresta - do estado do Rio Grande do Sul são amplamente relatadas na literatura (ZARTH, 1997; ANDREATTA, 2003; MIGUEL, 2009; FRANTZ; SILVA NETO, 2015), sendo que, grosso modo, a 
formação florestal predomina na metade norte do estado, e a formação de campo, na metade sul (FRANTZ; SILVA NETO, 2015). Esta característica implica, para Miguel (2009), a existência de duas grandes linhas de evolução e diferenciação dos sistemas agrários: uma que ocorre em áreas fisiográficas originalmente cobertas por uma vegetação de campo, e outra que ocorre nas áreas fisiográficas originalmente cobertas por uma vegetação de floresta.

Há espaços onde estas duas grandes linhas evolutivas se entrecruzam, formando o que Miguel (2009) chama de "áreas de tensão ecológica". A região das Missões se encontra em uma dessas áreas de encontro (FRANTZ; SILVA NETO, 2015), e, neste contexto, a análise de paisagem realizada no município de Rolador revela que, certamente, trata-se de um município muito representativo dessa dualidade.

Quanto a isso, cabe destacar um fato interessante. Os municípios limítrofes a Rolador evidenciam essa dualidade de suas formações vegetais: enquanto São Luiz Gonzaga, Mato Queimado e Caibaté são majoritariamente marcados pela ocorrência de campos, os demais municípios (Salvador das Missões, São Pedro do Butiá e Roque Gonzales e Dezesseis de Novembro) são caracterizados como uma região de floresta, sendo amplamente ocupados por frentes de colonização. Rolador é, portanto, composto por este mosaico de campo/floresta. No entanto, para este trabalho, o zoneamento não será dividido apenas em dois compartimentos (campo e floresta), posto que a região de campo possui grande heterogeneidade e, por isso, convém dividi-la em duas: uma composta por campo nativo constituído sobre solos altamente mecanizáveis, e outra na qual a mecanização torna-se inviável por conta do afloramento da rocha subjacente, ou simplesmente por ser um solo muito raso, jovem e pedregoso.

Desse modo, a análise em questão será realizada considerando que houve duas evoluções distintas, uma que ocorre na região de floresta, e outra que ocorre na região de campo; todavia, a partir de certo momento, configura-se uma terceira linha evolutiva, fazendo com que, atualmente, seja possível delimitar três zonas no município de Rolador. Cabe destacar, no entanto, que não se trata de limites inultrapassáveis e, portanto, certamente houve/há uma imbricação significativa entre essas zonas. Far-se-á uma breve descrição dessas áreas a partir de agora. 


\subsection{Zona 1}

Essa zona, que ocupa aproximadamente $50 \%$ do território municipal e está localizada a norte e a sudoeste do município (em direção aos municípios de Cerro Largo, Salvador das Missões, Dezesseis de Novembro e São Luiz Gonzaga) é considerada uma área composta originalmente por florestas. Mesmo que parte dessa região seja utilizada para o cultivo de grãos e cereais, é possível perceber grandes fragmentos de mata nativa.

Segundo Miguel (2013), as regiões de floresta são caracterizadas pela ocorrência de floresta ombrófila densa ou mista e floresta estacional decidual. Por meio da análise de paisagem, observou-se a presença de solos pedregosos e pouco profundos (cambissolo e neossolo regolítico), mas também alguns pontos com solos mais intemperizados (latossolos), sendo que a topografia dessa região possui certa ondulação. Além disso, a altitude nestas áreas oscila entre 280 e 320m. Estas áreas de florestas não são priorizadas por criadores de gado, uma vez que não dispõem de pastagens nativas para seus animais, sendo nessas áreas, portanto, que as frentes de colonização - organizadas ou não - se instalaram inicialmente. Nesses locais, era possível utilizarem-se técnicas e ferramentas dominadas pelos imigrantes, principalmente na agricultura de derrubada e queimada.

Nesta região, há certa heterogeneidade quanto à condição socioeconômica aparente. Se, por um lado, é possível observar situações nas quais a condição estrutural das instalações é precária, por outro lado, há também unidades de produção que, aparentemente, possuem uma boa condição financeira. Geralmente, esta última condição, do ponto de vista das práticas agropecuárias, tende a estar associada a áreas melhores, e a pecuária leiteira tende a estar presente na base produtiva. Tratando-se da acessibilidade, pode-se considerar que essa região é desfavorecida, se comparada com as outras regiões do município, principalmente por conta das más situações das estradas e acessos principais.

\subsection{Zona 2}

A zona 2 é parte da região de campo, que é composta por solos aptos à mecanização, ou seja, trata-se de solos muito intemperizados, não pedregosos e profundos, geralmente 
latossolos e nitossolos. Esta zona ocupa aproximadamente 35\% da área total do município e, grosso modo, está localizada a sudeste do município.

Como características gerais, uma área de campo é considerada como aquela constituída por estepes e savanas do tipo arbóreo aberto, parque ou gramíneo-lenhoso (MIGUEL, 2013). O relevo pode ser caracterizado como plano, e sua altimetria varia até 230 metros. A análise de paisagem evidenciou uma predominância de vegetação original rasteira e de hábito prostrado (característica de região de campo), mesmo que atualmente grande parte dessa área seja utilizada para o cultivo de grãos. Por conta dessas características, essa é uma região na qual a presença de unidades de recebimento de grãos é muito comum, sejam elas cooperativas ou empresas privadas.

Desse modo, o campo nativo já não faz mais parte da paisagem agrária, visto que há uma tendência de que as unidades de produção sejam altamente capitalizadas com estruturas produtivas renovadas e adaptadas à produção em grande escala. Além disso, em função desta última característica, a densidade demográfica parece ser muito baixa, dada a aparente concentração fundiária. As condições das estradas locais são consideravelmente boas, característica que destoa das demais regiões.

\subsection{Zona 3}

A zona 3 é também composta por campo, assim como a zona 2, mas há uma diferença fundamental: nesta região, os solos são pouco intemperizados (cambissolo, neossolo litólico e regolítico), muito pedregosos e, inclusive, com afloramento da rocha subjacente em alguns pontos. Em torno de $15 \%$ da área do município são ocupados por essa zona.

Inicialmente, a diferença em relação aos solos não impacta significativamente na evolução dos sistemas agrários de campo; no entanto, a partir da década de 60, essa característica é determinante para a exploração dessas terras, posto que a mecanização que é preconizada pela Revolução Verde torna-se inviável por conta da condição de solo (raso e pedregoso) e, por isso, a bovinocultura de corte segue sendo uma das principais atividades econômicas dessa região até os dias de hoje (MIGUEL, 2013). 
Nessa região, há unidades de produção que, aparentemente, possuem alto grau de capitalização e dedicam-se à produção de gado de corte. Geograficamente, essa região localiza-se a noroeste do município de Rolador e faz divisa com Dezesseis de Novembro e São Pedro do Butiá.

\section{Evolução e diferenciação dos sistemas agrários}

Como sugerido anteriormente, a reconstituição da evolução aqui proposta será realizada em dois momentos: o primeiro contemplando as regiões de campo, e o segundo, as áreas de floresta, com exceção do Sistema Agrário Indígena e Jesuíta, que antecedem os demais sistemas agrários e serão descritos de forma paralela, uma vez que ocupam ambas as regiões - campo e floresta.

\subsection{Sistema agrário indígena $(\ldots-1626)$}

O Sistema Agrário Indígena teve início com a colonização do espaço agrário gaúcho por populações pré-colombianas de caçadores/coletores (especialmente do grupo Gês), às quais se juntaram, mais recentemente, populações indígenas de agricultores/caçadores especialmente Tupi-Guaranis (MIGUEL, 2013).

Os indígenas da tribo Guarani costumam ocupar prioritariamente áreas de floresta (FRANTZ; SILVA NETO, 2015), no entanto se considera que neste período histórico tal ocupação, mesmo que não de forma homogênea, ocupou toda a área pertencente ao município, incluindo campo e floresta, uma vez que migravam constantemente de um para outro, de acordo com suas necessidades.

Para Frantz e Silva Neto (2015), os indígenas praticavam a agricultura utilizando as técnicas de derrubada e queimada, cultivando mandioca, milho, batata-doce, feijão, abóbora, fumo, erva-mate e algodão, sendo que sua alimentação era complementada com a caça e a pesca.

Para desenvolver estas atividades, utilizam ferramentas manuais, e toda produção era destinada ao autoconsumo podendo haver, no entanto, trocas entre comunidades próximas. Este sistema agrário se estende até o ano de 1626, quando da chegada dos 
jesuítas no município (MIGUEL, 2013). Esta data pode ser precisada em função de que, naquele ano, inicia-se a construção da Redução de Nossa Senhora da Candelária do Caaçapamini, no local atualmente conhecido como Rincão dos Melo, localizado a $3 \mathrm{~km}$ do centro da cidade.

4.2 Sistema agrário jesuíta (1627 - 1756)

Com a chegada dos jesuítas da Companhia de Jesus (na pessoa do padre Roque González de Santacruz), fundou-se, em 1627, a Redução de Nossa Senhora da Candelária do Caaçapamini - ou simplesmente Redução de Caaçapamini. É importante destacar que os jesuítas, em 1636, abandonam essa região pelo temor da ação dos bandeirantes paulistas e voltam apenas algumas décadas depois, em 1687, onde se constituíram os "Sete Povos das Missões" (GOMES, 1980). Neste segundo momento, a redução foi construída em São Luiz Gonzaga, da qual Rolador passou a fazer parte.

Essa ação jesuítica, para Frantz e Silva Neto (2015), tinha por objetivo a catequese do índio pelo convencimento cultural e religioso, inserindo-o de forma ativa e funcional na dinâmica expansionista do colonialismo mercantil. A partir desse período, introduziram-se também bovinos de raças ibéricas (através dos jesuítas), que se disseminaram rapidamente pelas regiões de campos e eram caçados visando à exploração do couro (MIGUEL, 2013).

Nesse sentido, Gomes (1980) relata que até a primeira entrada dos padres na região não havia registro de nenhuma espécie de gado e nem mesmo de equinos, sendo que os jesuítas trouxeram do outro lado do rio Uruguai alguns equinos, gado vacum e inclusive bovinos leiteiros. Em função de suas grandes criações de gado, os jesuítas procuraram ocupar regiões com extensas áreas de pastagem nativa: a região de campo. É necessário considerar, no entanto, o fato de que, possivelmente, utilizassem áreas de floresta para o cultivo dos alimentos e inclusive da erva-mate, a qual tinha certo valor econômico.

As reduções eram muito produtivas, e o excedente agropecuário era comercializado com Buenos Aires e Santa Fé, de modo que o pagamento por esses produtos era importante para a compra de utensílios e ferramentas (GOMES, 1980; SEPP, 1980). Dessa forma, considera-se que os jesuítas ocuparam ambas regiões - campo e floresta - uma vez que a produção de alimentos era realizada em regiões de floresta em função da limitação das 
ferramentas da época para o cultivo do campo. Outro ponto importante a ser destacado é o da erva-mate, produto muito valioso aos espanhóis, cujo cultivo se localiza nas florestas, sendo o índio designado para realizar a coleta (ANDREATTA, 2003).

O final deste sistema agrário ocorre por volta de 1756, quando, em consequência do Tratado de Madri, assinado em 1750, foram expulsos os jesuítas e os indígenas pelos exércitos português e espanhol (GOMES, 1980).

4.3 Evolução e diferenciação de sistemas agrários na região de campo

A partir da retirada dos jesuítas da região, ocorre uma evolução diferenciada nas regiões de campo e de floresta. Esta seção tratará de relatar a evolução e diferenciação dos sistemas agrários na região de campo. Foram evidenciados os seguintes Sistemas Agrários (SA): SA Estancieiro/Tropeiro, SA das Fazendas e, a partir deste, a bifurcação em SA da Bovinocultura Extensiva e SA das Monoculturas.

\subsubsection{Sistema Agrário Estancieiro/Tropeiro (1757 - 1919)}

A expulsão dos jesuítas do território missioneiro como um todo culminou no surgimento do sistema agrário aqui denominado como Estancieiro/Tropeiro. É necessário destacar que a segunda metade do século 18 caracterizou-se pela decadência do que foram as reduções, por causa do abandono a que são lançadas, quer pela administração espanhola, que sucede os jesuítas, quer pela portuguesa, que a substitui (RUCKERT, $1997^{4}$ apud FRANTZ; SILVA NETO, 2015).

Durante essa época, inicia-se na região a atuação dos tropeiros, responsáveis pela logística das tropas até o sudeste do Brasil. Esta região de campo desperta um interesse econômico, uma vez que a grande quantidade de gado deixada pelos jesuítas já em sua primeira investida na região tornava-se objeto de grande interesse (FRANTZ; SILVA NETO, 2015).

\footnotetext{
${ }^{4}$ RUCKERT, A. A. A trajetória da terra: ocupação e colonização do Centro-Norte do Rio Grande do Sul, 18271931. Passo Fundo: Ediupf, 1997.
} 
Este período histórico, como aponta Miguel (2013), teve como elemento de base o apresamento dos bovinos e muares xucros e sua condução a pé para as regiões do sudeste do Brasil, situação ocorrida devido à descoberta de ouro em Minas Gerais, que passou a demandar uma quantidade crescente de alimentos e animais de transporte.

Além disso, a atuação dos militares na região, após certo período de atuação dos tropeiros, possibilitou também seu acesso às terras, sendo que os campos nativos foram conquistados pelos futuros estancieiros por meio da simples obtenção de concessão, cedida pelas autoridades militares locais (MIGUEL, 2013). Dessa forma, para este autor, militares e tropeiros conseguiram, a preços irrisórios, vastas áreas de campo nativo, principalmente por meio da "venda" destas áreas pelas autoridades.

A atuação dos tropeiros no município de Rolador pode ser observada pelas rotas dos tropeiros. Uma destas rotas é chamada de Estrada das Missões, que saía de São Borja, passava por Santo Ângelo e seguia em direção à Palmeira das Missões, passando muito próximo, portanto, do município hoje denominado Rolador.

Em relação ao sistema de cultivo, como a principal atividade era a captura de animais, não havia necessidade de os meios de produção serem utilizados como ferramentas, por exemplo. Havia, provavelmente, a presença de mão de obra escrava e contratada para que houvesse o recolhimento desses animais (FRANTZ; SILVA NETO, 2015).

A diminuição da demanda por estes animais, aliada ao aparecimento das charqueadas, condicionou a desestruturação deste que foi um importante sistema agrário da região de campo (MIGUEL, 2013). Além disso, o abate indiscriminado de animais nos pampas gaúchos pode ter contribuído naquele momento.

\subsubsection{Sistema Agrário das Fazendas (1920 - 1959)}

Nesta época, ocorreu uma mudança importante no mercado do gado, que passa a ter maior importância, já que poderia ser destinado às recém-criadas charqueadas no Rio Grande do Sul. Para Andreatta (2003), no início do século XX, os fazendeiros que criavam e exportavam muares para o centro do país passaram a dedicar-se exclusivamente à bovinocultura, e o gado seguiu sendo criado em sistema extensivo; no entanto, houve o 
cercamento das fazendas e a demarcação desse gado, fato que modificou profundamente a dinâmica produtiva do gado bovino.

Miguel (2013) lembra que a implantação de frigoríficos no Rio Grande do Sul também teve grande importância para a efetivação deste sistema agrário, principalmente em função das novas exigências do mercado e do aumento da disponibilidade de bens e serviços. É preciso lembrar que esta é uma época de importantes transformações do campo gaúcho, uma vez que agora o foco das atividades não é mais a captura de muares, mas sim a criação de bovinos de corte, ou seja, há uma necessidade de aperfeiçoamento das condições de produção.

Para Frantz e Silva Neto (2015), além do cercamento dos campos, pelo menos parcialmente, este processo condicionou uma sensível melhora das características genéticas dos rebanhos. No entanto, os autores destacam que a abolição do trabalho escravo provocou o que se chamou de "crise de braços". Essa mudança ocorre no momento de maior demanda de trabalhadores, em virtude do cercamento das fazendas (ANDREATTA, 2003).

A paisagem do município de Rolador evidencia esse processo de forma muito clara, uma vez que a porção do município constituída por campo é amplamente composta por grandes propriedades (cercadas, geralmente), que é uma característica histórica herdada dos períodos estancieiro e de fazendas. Esta versão é confirmada pela população local.

Assim, é possível constatar que a principal atividade nessas áreas foi a criação de gado bovino, que seria posteriormente destinado aos frigoríficos. As atividades internas à propriedade eram realizadas por mão de obra contratada, e não havia necessidade de equipamento e ferramentas para manejo do solo, visto que se tratava de criação de gado em pastagem nativa. Este sistema agrário se estende até a década de 1960, quando ocorrem a crise da pecuária e, posteriormente, a entrada do pacote tecnológico proposto pela II Revolução Agrícola Capitalista, utilizando os termos de Mazoyer e Roudart (2010). A partir deste momento, ocorre uma bifurcação, desenvolvendo-se concomitantemente dois sistemas agrários nessa mesma região de campo: o sistema agrário das monoculturas e o sistema agrário da bovinocultura extensiva. 


\subsubsection{Sistema Agrário das Monoculturas (1960 - ...)}

O final da década de 50 e a década de 60 se caracterizam como um período importante no contexto agrário do município de Rolador. A crise ${ }^{5}$ da pecuária do norte gaúcho afetou diretamente os grandes criadores de gado, de forma que é muito provável que os sistemas de criação de gado bovino tornam-se cada vez menos interessantes do ponto de vista econômico.

Esta mesma época também é conhecida como o momento da entrada dos pacotes tecnológicos da II Revolução Agrícola Capitalista ou, simplesmente, da Revolução Verde. Estes pacotes suprem as limitações e restrições para o aumento da produção agrícola através da intensificação do uso de insumos de origem industrial (agrotóxicos, adubos químicos, etc.), da motomecanização, da modernização das instalações (aviários e pocilgas, estufas e galpões, etc.) e da adoção de plantas e animais selecionados (MIGUEL, 2013).

Em paralelo a isso, firma-se, no Brasil, nesta época (década de 60), uma política de fomento ao uso desses insumos e equipamentos na agricultura, sendo que o principal meio para institucionalização desta política foi o crédito rural, principalmente direcionado para as culturas de trigo e arroz (FRANTZ; SILVA NETO, 2015). No município de Rolador, no entanto, o trigo se destacou neste momento nas áreas de campo, e, a partir de então, ocorre uma distinção importante nas áreas de campo, assim como em sua evolução, uma vez que seus solos foram corrigidos com a aplicação de calcário e fertilizante.

Superada esta restrição química dos solos e se tratando de solos aptos para motomecanização (não pedregosos e não rasos), tornou-se possível a ampla adoção dos pacotes da Revolução Verde nessas áreas, ou seja, as áreas com vegetação nativa são minoria, o que não acontece na região de campo com solos muito jovens, rasos e pedregosos. Ou seja, existem duas áreas de campo, e apenas aquela mais apta a utilizar a mecanização agrícola adaptou-se a essa nova forma de produção, agora com intensa mecanização.

\footnotetext{
${ }^{5}$ Andreatta (2003) relata que a crise surge a partir do momento em que os fazendeiros do Planalto obrigatoriamente passam a concorrer com os fazendeiros fronteiriços, o que contribuía para reduzir seus rendimentos. Para contornar essa situação, os fazendeiros do Planalto aumentavam a lotação de seus campos; no entanto, como suas pastagens eram de menor qualidade, ocorreu uma excessiva exploração das pastagens, que culminou na degradação dos recursos naturais e posterior crise deste sistema.
} 
Após o forte incentivo à cultura do trigo, a cultura da soja ganhou muita força na região e hoje, certamente, é mais importante economicamente que sua antecessora, embora seja muito comum os agricultores realizarem o que se convencionou chamar de "binômio trigo-soja", ou seja, o cultivo da soja no verão e trigo no inverno. A cultura do milho também é expressiva no município, mas tem apresentado certo declínio nos anos recentes, conforme a Figura 1. Ambas as culturas aqui retratadas são produzidas em sistema de monocultura (nos antigos campos de pastagem nativa) e com alto grau de capitalização.

Figura 1 - Área colhida (ha) dos principais grãos produzidos no município de Rolador-RS

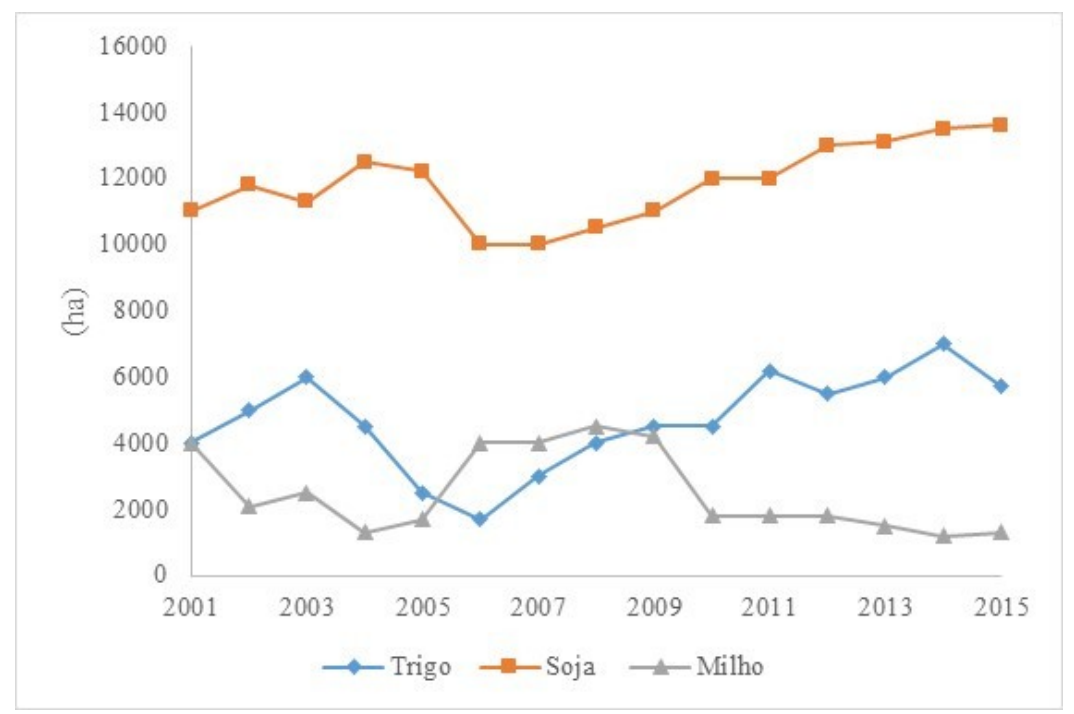

Fonte: Dados brutos de FEEDADOS (2015). Elaboração própria (2018).

De forma geral, é possível estabelecer que este sistema agrário, consolidado na década de 60 - e que se estende até os dias de hoje -, é baseado na produção de grãos (soja, trigo e milho) em monocultura com utilização de mão de obra contratada e familiar.

\subsubsection{Sistema Agrário da Bovinocultura Extensiva (1960 - ...)}

Os pacotes da Revolução Verde não foram adotados nas áreas de campo compostas por solos jovens, rasos, pedregosos e, por vezes, com afloramento da rocha subjacente, uma vez que nestes a inserção da motomecanização foi praticamente impossível. Assim, nessas áreas, é possível observar até os dias de hoje grandes propriedades ocupadas ainda por pastagens nativas, sob as quais se pratica a bovinocultura extensiva. 
A vegetação nativa, nas unidades de produção da propriedade, ocupa quase a totalidade da área, com exceção de pequenas áreas - quando existem - destinadas à produção de alimentos como o feijão, a mandioca e a batata-doce, os quais são destinados ao autoconsumo, assim como pequenas criações (frangos, suínos).

A principal atividade econômica se baseia, portanto, na venda de bovinos de corte. Este novo sistema agrário - que se configura na década de 60 e se perpetua até hoje possui algumas diferenças em relação ao sistema agrário que o antecedeu, principalmente no que se refere aos meios de produção (embora as áreas de campo nativo demandem pouca mecanização, houve a introdução das roçadas e a adoção de insumos externos) e à genética dos animais (a incorporação de raças melhoradas é algo comum).

As unidades de produção que não são familiares, ou seja, os proprietários destas terras que não habitam nem utilizam sua mão de obra nessas propriedades são maioria. Assim, a região de campo composta por solos pedregosos foi, de certa forma, excluída dos "pacotes da Revolução Verde". Cabe aqui uma importante reflexão: o avanço tecnológico será capaz de tornar estas áreas aptas ao monocultivo de grãos? Em caso de resposta afirmativa, quais os reflexos deste processo?

\subsection{Evolução e diferenciação de sistemas agrários na região de floresta}

A evolução e diferenciação dos sistemas agrários da região de floresta no município de Rolador, embora em constante imbricação, diferem profundamente daqueles compostos por campos, principalmente no que se refere à sua ocupação. Ou melhor, “[...] não por determinismo geográfico simplesmente, mas por fatores conjunturais, o processo de ocupação do território sulino está estreitamente ligado a condições naturais da vegetação" (ZARTH, 1997).

Os sistemas agrários dessa região, posteriormente ao sistema agrário indígena e jesuíta que ocupam ambas regiões (campos e floresta), foram divididos em três: SA Caboclo, SA Colonial Inicial, SA Colonial Contemporâneo. 


\subsubsection{Sistema Agrário Caboclo (1757 - 1919)}

Após a expulsão dos jesuítas da região das Missões, inicia-se, na região de campo, o sistema agrário estancieiro/tropeiro com a captura de muares e a criação de gado. Essa dinâmica influencia certamente o espaço agrário das florestas da região.

Com a saída dos jesuítas, uma parte dos índios remanescentes dos conflitos com espanhóis e portugueses, agora em número bem menor, será empurrada para o interior das florestas (SILVA NETO, 1997). No município de Rolador, este dado tende a ser confirmado, uma vez que os Guaranis normalmente preferiam áreas próximas a rios, e estas regiões de florestas de Rolador estão localizadas próximas ao rio ljuí e ao arroio Rolador.

Surge, a partir deste momento, uma figura importante: os caboclos, que, para Frantz e Silva Neto (2015), eram trabalhadores em terras de campo e mato e com origens das mais variadas, entre as quais, segundo os autores, destaca-se a possibilidade de serem descendentes 1) de bandeirantes e tropeiros paulistas que, em suas sucessivas incursões, se relacionavam com mulheres índias; 2) de encontros fortuitos e quase sempre violentos entre militares com a população civil durante os conflitos pelo controle da região; 3) de índios sobreviventes e aculturados.

A partir do início do século 19, inicia-se a consolidação das grandes estâncias na região de campo, onde o caboclo poderia trabalhar como assalariado, enquanto os demais membros da família trabalhavam em suas áreas de floresta, praticando a agricultura de derrubada e de queimada (ANDREATTA, 2003). Além disso, a exploração e comercialização de erva-mate dava ao caboclo, segundo esta autora, uma relativa autonomia.

Neste sistema agrário, não só a paisagem local pode ser considerada preservada, como a erva-mate e também o trabalho assalariado nas estâncias o principal produto de interesse econômico. As ferramentas utilizadas na produção de alimentos (milho, feijão, amendoim, batata-doce) eram geralmente manuais. Esta dinâmica agrária perdura até a chegada das frentes de colonização na região, que datam das primeiras décadas do século XX (CALLEGARO; TREVISAN, 2015; TONI; MACHADO; SILVA NETO, 2016) e ocupam as áreas de floresta, predominantemente. 


\subsubsection{Sistema Agrário Colonial Inicial (1920 - 1959)}

A chegada dos imigrantes europeus na região estabelece uma modificação na dinâmica agrária da região das florestas. A frente de colonização ocupa estas áreas principalmente em razão da prática da agricultura de derrubada e queimada e também porque nessas áreas os estancieiros gaúchos não tinham objeção alguma às frentes de colonização, desde que não ocupassem suas áreas de campo (FRANTZ; SILVA NETO, 2015).

Estudos realizados nos municípios vizinhos (Cerro Largo e São Pedro do Butiá fortemente marcados pela colonização) evidenciaram que a colonização predominante na região foi de etnia alemã e oriunda das colônias velhas do Rio Grande do Sul. Os lotes adquiridos na época eram relativamente homogêneos e continham 25 hectares (TONIN; MACHADO; SILVA NETO, 2016; MACHADO; TONIN; SILVA NETO, 2016).

É muito importante destacar que, diferentemente do que aconteceu em Cerro Largo e São Pedro do Butiá, a chegada dos colonos europeus na região de florestas do município de Rolador não se deu de forma organizada, por meio de uma comissão. Também é possível que muitas famílias tenham atravessado o rio ljuí em busca de terras disponíveis à ocupação (neste caso, no município de Rolador). Embora também oriundos das colônias velhas, esses colonos eram menos capitalizados e, portanto, com menor poder aquisitivo.

Restaram as zonas de florestas não ocupadas pela comissão. Estas regiões, no entanto, estavam ocupadas pelos caboclos que ali habitavam. Porém é importante pontuar que os colonos europeus, mesmo que sem o apoio direto do Estado, tomaram posse dessas terras em grande medida, mas não em função de seu poder aquisitivo - embora, por vezes, o fosse - e sim pelo acesso à informação necessária para sua obtenção oficial. Esta informação é herdada de seus antecessores das colônias velhas, que tinham todo o apoio jurídico do Estado para ocupação e posse de terras com tal tipo de ocupação cabocla. Para Zarth (1997), o Estado entendia que eram os colonos imigrantes os encarregados do desenvolvimento agrícola, e não os caboclos, sendo esta a diferença fundamental entre tornar-se sem-terra e empregado (caboclos) ou dono das terras (colono europeu).

Reitera-se que a ocupação das terras de florestas, onde hoje se localiza o município de Rolador, deu-se de forma desordenada, diferente do que aconteceu nos municípios vizinhos. Nestes últimos lugares, mesmo que tenha ocorrido uma colonização privada e não 
organizada diretamente pelo Estado, respeitaram-se alguns critérios, como acesso à água e glebas homogêneas para todas as famílias de imigrantes (nestes casos, europeus não ibéricos). Por outro lado, não há relatos de que isso tenha acontecido em Rolador, pelo contrário, todas as informações coletadas corroboram a tese de que as famílias com menor poder aquisitivo (portanto, sem o amparo de uma comissão organizadora) atravessaram o rio e protagonizaram uma ocupação desordenada nas áreas de floresta.

Desse modo, grande parte dessas famílias acessou terras menos aptas à produção agropecuária e, por assim ser, teve grande dificuldade no processo de acumulação de capital quando comparada às famílias que ocuparam as terras de Cerro Largo, por exemplo. Ademais, como o processo de ocupação foi desordenado, houve também uma diferenciação na acumulação de riquezas entre as próprias famílias que passaram a habitar as florestas de Rolador, isto porque, mesmo que marginais, essas terras também eram muito heterogêneas e, por conseguinte, mais ou menos aptas às práticas agrícolas. Essa desigualdade no acesso à terra propiciou uma diferenciação social que se faz perceber até os dias de hoje.

No que se refere à produção agrícola, realizavam o cultivo das áreas por meio da derrubada e queimada, com plantio e semeadura manual e com uso de tração animal, onde predominava a produção para subsistência e troca de produtos, tendo o porco-banha e o feijão grande importância na dinâmica local. Trata-se, neste caso, de agricultores familiares e sem mão de obra contratada. O final desse sistema agrário está condicionado por algumas alterações na lógica produtiva, principalmente no que se refere à adoção de um novo conjunto de meios de produção, incluindo novas espécies de cultivo e mecanização intensiva.

\subsubsection{Sistema Agrário Colonial Contemporâneo (1960 - ...)}

A partir da década de 60, a região, que já é ocupada pelos colonos imigrantes no município, em grande parte de origem alemã, sofre algumas modificações importantes. Estas alterações, certamente, estão mais relacionadas com os meios de produção do que com novas ocupações.

Pelas características físicas dos solos dessa região, o pacote tecnológico da Revolução Verde não pôde ser adotado em sua plenitude. No entanto, alguns novos elementos 
começaram a ser utilizados por colonos, aqui denominados de agricultores familiares. Estes novos elementos dizem respeito a ferramentas como motosserras, roçadeiras e, em alguns casos, tratores e implementos agrícolas de pequeno porte.

Além disso, a utilização de insumos químicos torna-se recorrente, principalmente corretores de $\mathrm{pH}$, fertilizantes, fungicidas, herbicidas e inseticidas. Estes produtos são usados nas pequenas produções (com variedades melhoradas) de olerícolas, milho, feijão e soja nesta última em menor quantidade. A partir da década de 70 , surge na região a produção de alfafa (amplamente utilizada na produção de feno para alimentação de equinos), a qual, geralmente, é realizada por estes agricultores familiares

Além das culturas citadas anteriormente, produziram-se também os alimentos destinados ao autoconsumo, como batata-doce, mandioca, frutas e olerícolas de modo geral, assim como pequenas criações. No início deste período, ocorre também uma mudança importante em outro componente da matriz produtiva, na qual o suíno "tipo banha" passa a dar lugar ao "suíno tipo carne" em função da decadência do preço da banha e ascensão do preço da carne (TONIN; MACHADO; SILVA NETO, 2016). Nessas unidades de produção, o índice de capitalização tende a ser pouco expressivo.

Existe uma situação nesta região que precisa ser destacada. Houve a construção de um represamento no rio ljuí (UHE São José - 2011), na altura do município de Salvador das Missões, um dos limites ao norte de Rolador. Este barramento inundou uma pequena área da região de floresta. A encosta localizada à montante do represamento é hoje constituída por lotes destinados ao lazer e adquiridos principalmente por habitantes da zona urbana dos municípios do entorno. Neste trabalho, essa região foi desconsiderada, visto que não é mais representada por sistemas de produção agropecuários, mas sim por chácaras de lazer.

Em alguns pontos da zona de floresta, é possível perceber também que, a partir da década de 90, a atividade leiteira passa a ter alguma importância financeira para os agricultores e, atualmente, caracteriza-se por ser uma das principais atividades econômicas. Grande parte das unidades de produção de leite - tema principal deste trabalho - está situada nessa região.

Nos últimos anos, porém, o processo de especialização produtiva intensificou-se. Por exemplo, as empresas que recolhem o leite estabeleceram um limite diário mínimo de produção de aproximadamente 100 litros por dia, ou seja, uma parcela importante dos 
agricultores foi excluída do processo produtivo, pois sua produção não alcançava esse patamar, independentemente dos resultados econômicos. Alguns dados disponibilizados pela FEE (2015) auxiliam na compreensão dos reflexos deste processo, conforme Figura 1. Esse conjunto de dados deixa claro que houve uma diminuição do número de vacas ordenhadas e um aumento importante na produção total, ou seja, trata-se de um aumento de escala produtiva com base na intensificação.

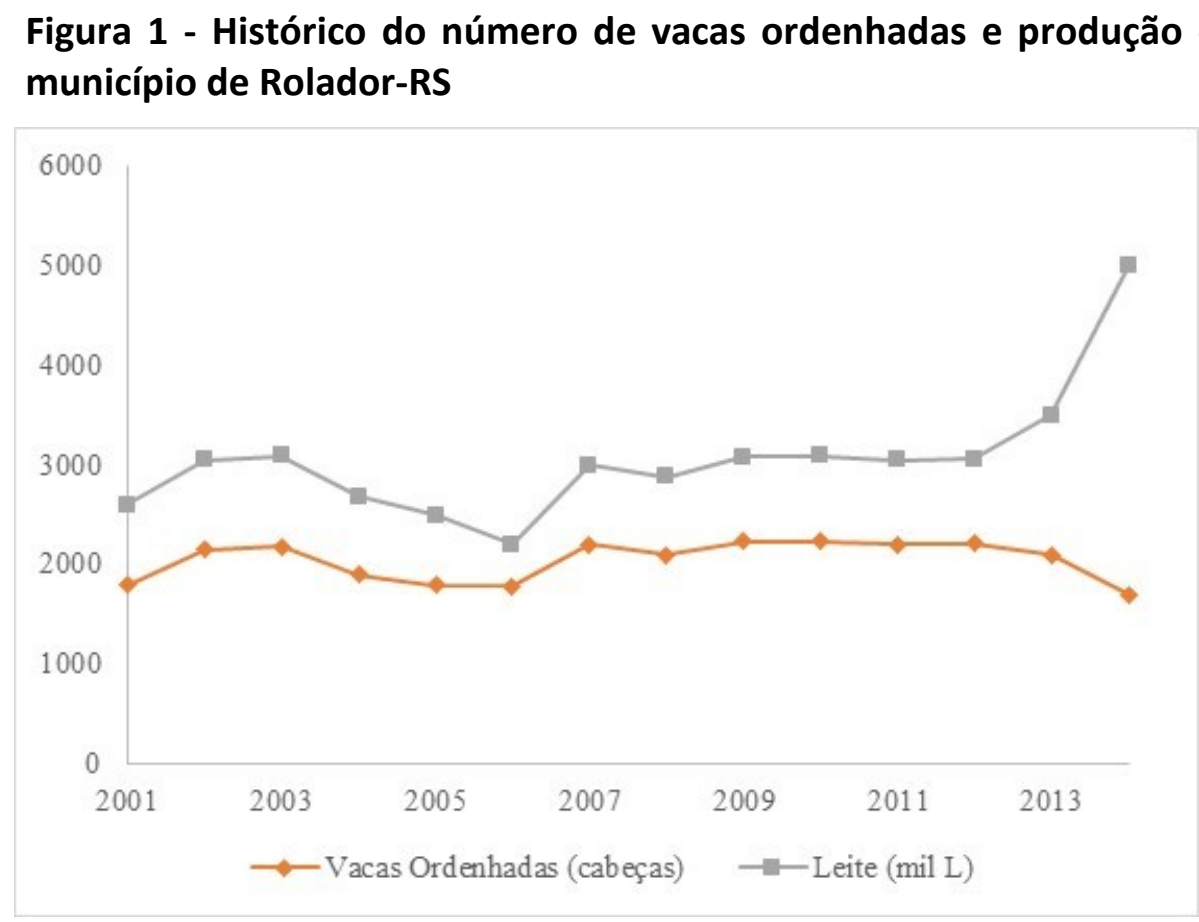

Fonte: Dados brutos de FEEDADOS (2015). Elaboração própria (2018).

Além disso, nas regiões de floresta, observam-se atualmente algumas experiências interessantes com produção de base ecológica em processo de transição para certificação enquanto produção orgânica. Ou seja, trata-se da utilização de sistemas de produção com alto valor agregado. Assim, mesmo que a agricultura familiar também esteja presente nos outros dois sistemas agrários que constituem o período atual de Rolador, é neste sistema agrário que ela é mais expressiva. Seguem abaixo (Quadro 1) alguns dados a respeito dessa importante categoria. 
Quadro 1 - Índices relacionados à agricultura familiar do município de Rolador-RS

\begin{tabular}{|c|c|c|c|c|c|}
\hline \multicolumn{2}{|c|}{ Indicadores Socioeconômicos (2010) } & \multicolumn{3}{c|}{ Agricultura Familiar (2006) } \\
\hline $\begin{array}{c}\text { Renda per } \\
\text { capita (R\$) }\end{array}$ & $\begin{array}{c}\text { \% de } \\
\text { extramamente } \\
\text { pobres }\end{array}$ & $\begin{array}{c}\text { \% vulneráveis } \\
\text { à pobreza }\end{array}$ & Estabelecimentos & $\begin{array}{c}\text { Pessoal } \\
\text { ocupado }\end{array}$ & $\begin{array}{c}\text { DAP - pessoa } \\
\text { física }\end{array}$ \\
\hline 767,63 & 6,77 & 46,35 & 787 & 1.848 & 487 \\
\hline
\end{tabular}

Fonte: Dados Brutos de Brasil (2015). Elaborado pelo Autor (2018).

Percebe-se, por exemplo, que o número de Declarações de Aptidão ao PRONAF (DAP's) é consideravelmente inferior ao número de estabelecimentos da agricultura familiar. Vale lembrar que há a possibilidade de existir mais de uma DAP por estabelecimento, o que aumentaria essa diferença se fosse avaliado o número de DAP por estabelecimento. De todo modo, esta diferença permite concluir que parte dos agricultores não possuem acesso à maioria das políticas públicas para agricultura familiar, uma vez que a DAP costuma ser um pré-requisito para esse acesso. Isso pode ocorrer porque alguns agricultores podem não ter interesse em acessá-las, ou, então, não conseguem tal acesso por vários outros motivos, incluindo entraves burocráticos. Todavia, este assunto foge do escopo deste trabalho e pode ser tema de outro estudo igualmente importante.

\section{Condicionantes de um desenvolvimento desigual?}

A reconstituição de uma evolução e diferenciação de sistemas agrários em uma região composta por dois tipos de formação original - campo e floresta - revela uma dualidade interessante do ponto de vista da dinâmica agrária. Como se viu, o município de Rolador se encontra em uma zona de tensão ecológica, ou seja, está geograficamente posicionado no encontro destas duas grandes formações vegetais que ocorrem no Rio Grande do Sul.

Nesse sentido, mesmo se tratando de uma área pequena, é possível perceber como a evolução dos sistemas agrários deu-se de forma diferenciada, embora constantemente imbricadas. Esta diferenciação ocorreu desde o processo de ocupação dessas terras, no qual as áreas de florestas foram prioritariamente utilizadas para colonização, ao passo que as áreas de campo se mantiveram predominantemente marcadas pela pecuária extensiva. Mais 
recentemente, por volta da década de 60, a II Revolução Agrícola dos Tempos Modernos provocou profundas transformações no contexto agrário dessas áreas através de seus "pacotes tecnológicos".

A incorporação dos preceitos da segunda revolução agrícola não se deu, porém, em um processo de desenvolvimento geral e harmonioso, dado que dentre os múltiplos estabelecimentos agrícolas, apenas uma ínfima minoria conseguiu ultrapassar todas as etapas desse desenvolvimento (MAZOYER; ROUDART, 2010). A cada etapa, segundo sugerem estes autores, só podiam continuar a investir e progredir os estabelecimentos agrícolas que tivessem mínimas condições para gerar uma renda por trabalhador superior ao preço de mercado da mão de obra utilizada, de modo que esta renda é denominada patamar da renovação. Por esse motivo, o desenvolvimento dessas propriedades foi, então, desigual.

Soma-se a essa questão o fato de que a pesquisa agropecuária foi capaz de gerar apenas soluções parciais para os problemas reais da agricultura, e a extensão rural, agravando a situação, não dispunha de normas técnicas adaptadas à diversidade das condições de produção, e também, em grande medida, desconhecia a realidade socioeconômica de parte dos agricultores (DUFUMIER, 2010). Além disso, algumas condições naturais também atuaram como elementos de desvantagem para algumas unidades de produção no processo de desenvolvimento (MAZOYER; ROUDART, 2010). Nesta ocasião, por exemplo, a utilização de insumos químicos via crédito rural estava condicionada à disponibilidade de terras mecanizáveis (SILVA NETO et al., 2009).

No município de Rolador, esta realidade é facilmente observável na medida em que apenas aquelas terras que eram aptas à mecanização, isto é, não eram muito declivosas, possuíam solos não pedregosos e de perfil profundo, tiveram condições de incorporar todos os "pacotes tecnológicos" da Revolução Verde. No entanto, mesmo estando em condições ambientais privilegiadas, o nível de capitalização inicial certamente determinou quem seria capaz de seguir em frente no processo de desenvolvimento.

Este conjunto de elementos possibilitou a existência de dois sistemas agrários distintos na região de campo: um baseado em sistemas de produção altamente mecanizados, pouco demandantes em mão de obra e pautados na produção de grãos em grande escala, ou, então, na produção especializada de leite - também altamente 
mecanizada e especializada -, e outro que continuou tendo na bovinocultura de corte em sistema extensivo sua atividade principal, uma vez que nestas áreas a motomecanização não pôde ser incorporada. Além disso, a bovinocultura de corte já não era mais rentável como fora outrora.

Além dessas duas situações localizadas na região de campo, há também o sistema agrário que ocupa a zona de floresta, que, por estar inserido também em condições ambientais (solos consideravelmente pedregosos e topografia acidentada) e econômicas pouco favoráveis, ficou à margem do processo de modernização da agricultura. Observa-se, entretanto, que este não possui na pecuária extensiva sua principal renda, mas sim na produção de olerícolas e também de grãos em menor escala. É pertinente destacar que nestes dois últimos (colonial contemporâneo e bovinocultura extensiva), o nível de capitalização aparente é bastante reduzido, uma vez que não possuem as mesmas condições ambientais e econômicas dos demais, e, por isso, tornam-se incapazes de competir nesta mesma lógica.

Assim, num sistema agrário, à medida que certas unidades de produção acumulam capital, outras podem estar estagnadas, ou mesmo se descapitalizando (SILVA NETO et al., 2009), caracterizando um processo de desenvolvimento e crise na agricultura contemporânea, uma vez que as regiões marginais e os agricultores pobres foram, mais uma vez, deixados à margem desse movimento (MAZOYER; ROUDART, 2010).

Esta situação agrária de desigualdade social, em grande medida, é gerada por diferentes ações do Estado para o desenvolvimento. Como já mencionado, as três décadas pós-1964 foram fortemente marcadas pelo incentivo à produção primária, via modernização da agricultura brasileira, seja para abastecer e subsidiar o desenvolvimento da indústria nacional, seja para gerar saldos comerciais via exportação, e este incentivo foi, sem dúvidas, seletivo. Esta modernização, como se sabe, permitiu liberar uma grande quantidade de mão de obra do campo, e, no município de Rolador, mais uma vez, essa situação torna-se clara ao se observarem as unidades de produção de grãos, altamente mecanizadas e com baixa demanda de mão de obra.

Estes sistemas de produção tendem a não contribuir para um desenvolvimento equitativo e inclusivo, uma vez que são também caracterizados pela concentração da renda e pela liberação de grandes contingentes populacionais. Essa dinâmica é importante de ser 
analisada em função de que, à medida em que a disparidade da distribuição da renda vai aumentando, há, segundo Callegaro e Silva Neto (2004), uma tendência em se consumir cada vez menos bens e serviços locais, o que, por consequência, diminui o dinamismo da economia local.

O processo ocorrido no município de Rolador não é algo raro ou isolado, mas sim uma tendência que pode ser observada em várias regiões, onde políticas de desenvolvimento com este perfil foram implantadas. Estas políticas são também responsáveis por grande parte da diferenciação e da desigualdade social que hoje compõem a realidade agrária de muitos municípios. Rolador, portanto, é um caso interessante de ser analisado, pois permite refletir sobre os efeitos de um movimento que, por não considerar a diversidade e a complexidade dos sistemas agrários, contribuiu para um desenvolvimento desigual e seletivo, e, portanto, não equitativo da sociedade.

\section{Considerações finais}

Evidenciamos uma diferenciação importante na dinâmica dos sistemas agrários de Rolador, que se deu conciliando ação humana e espaço. Assim, os caminhos percorridos pelas populações humanas que constituíram os sistemas agrários observados, no espaço e no tempo, tiveram uma forte sinergia sobre as paisagens em que cada uma está inserida. Por exemplo, as regiões de campo, historicamente, foram utilizadas para a criação de gado; as regiões de floresta foram objeto de colonização, sobretudo nas primeiras décadas do século $\mathrm{XX}$.

Além disso, um dos principais acontecimentos que marcam este último período é o da Revolução Verde, de modo que a implantação de seus pacotes tecnológicos se tornou possível apenas em regiões aptas à motomecanização, ou seja, apenas parte da região antes constituída por campo pôde adotar esta lógica de produção, promovendo tamanhas mudanças a ponto de haver uma ruptura desse sistema agrário, dando origem ao sistema agrário das monoculturas e da bovinocultura extensiva.

Dito de outra forma, as unidades de produção estão fortemente sob a influência das características da paisagem que ocupam, bem como é necessário levar em conta a complexidade de cada sistema agrário e as estratégias que os agricultores podem colocar em 
prática diante de cada situação. O modelo de "desenvolvimento" estabelecido pela Revolução Verde possibilita compreender a complexidade das relações que se estabelecem pelos diferentes agentes que compõem um sistema agrário. Lembrando que neste caso trata-se de um município, mas as tendências globais tendem a ser extrapoladas para outras situações em condições similares, como grande parte dos municípios desta região do estado do RS.

Desta forma, a visão sistêmica fornecida por esta abordagem revela-se muito interessante ao possibilitar a compreensão das grandes tendências históricas, assim como suas rupturas - ou não - ao longo da história agrária de um espaço determinado, e, além disso, apresenta um ganho que reside no fato de construir um olhar ampliado, sem perder de vista o rigor científico.

\section{Referências}

ANDREATTA, A. Febre aftosa no Rio Grande do Sul no ano de 2000: uma análise das transformações ocorridas nos sistemas de produção dos agricultores produtores de leite de Jóia. 2003. (Mestrado em Desenvolvimento Rural) - Universidade Federal do Rio Grande do Sul, Porto Alegre, 2003. Disponível em http://www.lume.ufrgs.br/handle/10183/2860.

Acesso em: 17 jun. 2017.

CALLEGARO, S. S.; TREVISAN, L. P. Análise-diagnóstico da agricultura de Santa Rosa. In: Silva Neto B.; Basso, D. (orgs.). Sistemas agrários do Rio Grande do Sul: análise e recomendações de políticas. 2. ed. Ijuí: Unijuí, 2015. p. 286-196.

FRANTZ, T. L.; SILVA NETO, B. A formação histórica dos sistemas agrários do Rio Grande do Sul. In: SILVA NETO B.; BASSO, D. (orgs.). Sistemas agrários do Rio Grande do Sul: análise e recomendações de políticas (ed. 2, p. 286-196), ljuí: Unijuí, 2015.

GOMES, J. História de São Luiz Gonzaga. São Luiz Gonzaga: Gráfica A Notícia, 1980.

MACHADO, J. T. M.; TONIN, J.; SILVA NETO, B. Situação e perspectivas da agricultura do município de Cerro Largo (RS): um estudo baseado na análise-diagnóstico de sistemas agrários. Trabalho apresentado no Congresso da Sociedade Brasileira de Sistemas de Produção. Pelotas, 2016. Disponível em: http://www.sbsp.org.br/z1files/pub/146895000280900_SITUACAO-E-PERSPECTIVAS-DAAGRICULTURA-DO-MUNICIPIO-DE-CERRO-LARGO.pdf. Acesso em: 20- jun. 2017. 
MAZOYER, M.; ROUDART, L. História das Agriculturas do Mundo: do neolítico à crise contemporânea. São Paulo: Unesp, 2010.

MIGUEL, L. A. Entre os campos e as florestas: origem e evolução da agricultura no Rio Grande do Sul. Trabalho apresentado no Séminaire franco-brésilien: Dialogues contemporains sur la question agraire et l'agriculture familiale au Brésil et en France, AgroParisTech, Paris, 2013. Disponível em: http://www.ufrgs.br/pgdr/publicacoes/producaotextual/lovois-de-andrademiguel-1/miguel-I-a-entre-campos-e-florestas-origem-e-evolucao-da-agricultura-no-riogrande-do-sul-brasil-seminaire-franco-bresilien-dialogues-contemporains-sur-la-questionagraire-et-I2019agriculture-familiale-au-bresil-et-en-france-ladyss-et-agroparistech-paris. Acesso em: 15 ago. 2017.

MIGUEL, L. A.; MAZOYER, M.; ROUDART, L. Abordagem Sistêmica e Sistemas Agrários. In: MIGUEL, L. (org.). Dinâmica e Diferenciação de Sistemas Agrários. Porto Alegre: UFRGS, 2009. p. 11-38.

MIGUEL, L. Origem e evolução dos sistemas agrários no Rio Grande do Sul In: Miguel, L. (org.). Dinâmica e Diferenciação de Sistemas Agrários. p. 11-38. Porto Alegre: UFRGS, 2013

MORIN, E. O método: 1. A natureza da natureza. Paris: Seuil, 1977.

SCHMITZ, H. Abordagem sistêmica e agricultura familiar. In: Mota, D. M.; Schmitz, H.; Vasconcelos, H. E. M. Agricultura familiar e abordagem sistêmica. Aracajú: Sociedade Brasileira de Sistemas de Produção, 2005.

SEPP, A. Viagem às Missões jesuíticas e trabalhos apostólicos. Itatiaia: Itatiaia, 1980.

SILVA NETO, B. Estudos dos sistemas de produção agropecuários da região de Três de Maio/RS. ljuí: Unijuí, 1997.

SILVA NETO, B.; BASSO, D. Aplicação da Teoria dos Sistemas Agrários para a análise da agricultura do Rio Grande do Sul. In: SILVA NETO B.; BASSO, D. (orgs.). Sistemas agrários do Rio Grande do Sul: análise e recomendações de políticas. 2 ed. ljuí: Unijuí, 2015. p. 196-286.

TONIN, J.; MACHADO, J. T. M. SILVA NETO, B. (2016). Problematizando o desenvolvimento rural a partir de uma análise do sistema agrário do município de São Pedro do Butiá/RS. Trabalho apresentado no Congresso da Sociedade Brasileira de Sistemas de Produção. SBSP, Pelotas. Disponível em:

http://beneweb.yolasite.com/resources/Problematizando\%200\%20desenvolvimento\%20rur al\%20a\%20partir\%20de\%20uma\%20an\%C3\%A1lise\%20de\%20S\%C3\%A3o\%20Pedro\%20do\% 20Buti\%C3\%A1.pdf

ZARTH, P. A. História agrária do planalto gaúcho 1850-1920. Ijuí: Unijuí, 1997. 